\title{
Why do People Come? The Factors Influencing Public Library Visits
}

\author{
Li-Min Huang \\ University of Tennessee, USA \\ Ihuang23@vols.utk.edu \\ Iman Tahamtan \\ University of Tennessee, USA \\ tahamtan@vols.utk.edu
}

\begin{abstract}
Current study investigates what variables, including expenditures, services, and collections, can predict the total annual public library visits (VISITS) in the United States. The data source was the 2015 Public Library Service data and reports, and a multiple regression model was used to analyze the data in the $\mathrm{R}$ programming language. Results indicated that the best variables for predicating VISITS were a library's total operating expenditures, usage of public Internet-enabled computers per year, audio-physical units, total children programs, and video-physical units. The best subset model for predicting VISITS included the total number of public libraries, total operating expenditures, print materials, audio-physical units, total children programs, total young programs, and the usage of public Internet-enabled computers per year.
\end{abstract}

\section{INTRODUCTION}

Public libraries aim to fulfill users' information needs by providing a variety of facilities, resources, and services (Clubb, 2009). Public librarians have always taken efforts to increase reader visits, however, they have also gone through various challenges when enhancing people's motivation for visiting libraries in this digital era. For example, many public libraries have inadequate funding to cope with the drastic changes that technology brings (Clubb, 2009). With limited budget and labor power, it is urgent for public libraries to figure out the most influential factors on library visits and to determine the strategies for attracting users to libraries. The purpose of current study is to examine the key factors that could effectively predict public library visits. The findings begin to establish an empirical model on predicting factors that would influence public library visits in the U.S. and will have implications on policy planning and funding distribution of those public libraries. The main research questions in the study are: 1) Which variables are most important in predicting the total annual public library visits in the U.S.? 2) What is the best subset model for predicting the total annual public library visits in the U.S.?

\section{RELATED WORKS}

Bertot, et al. (2008) found that public libraries served as important workstations with Internet access for many people in their communities. Public library collections and services are also associated with library visitation. Sin and Kim (2008) analyzed data from the Public Library Service (PLS) and attributed public libraries with higher collections, more Internet terminals, and more branch libraries to having higher library visitation. This study further indicated that programs and collections related to children have significant impacts on library visits. Another study by Joo and Cahill's (2017) indicated that using printed children materials were viewed by parents as the primary reason to visit public libraries. Similarly, Hemmeter (2006) found that the households with children used public libraries more than those who didn't have children. The literature indicates that people visit public libraries for a variety of reasons such as using their collection, services, and spaces. However, it is not yet well understood what factors predict public library visits in the U.S.

\section{METHOD}

The data source for this study was the Institute of Museum and Library Services (IMLS) PLS reports for 2015. We included the 50 U.S. states and the District of Columbia. The dependent variable was VISITS (total number of persons entering the library for all purposes during that year), and independent variables included: POPUST (reported state total population estimate), NLIB (total number of public libraries), TOTOPEXP (total operating expenditures), BKVOL (print materials, including books and government documents), EBOOK (electronic books), AUDIOPH (audio-physical units such as audio cassettes and talking books), VIDEO_PH (video-physical units such as video tapes), LOANFM (inter-library loans received), KIDPRO (total children's programs), YAPRO (total young adult programs), PITUSR (uses of public Internet-enabled computers per year). We used multiple linear regression in the $\mathrm{R}$ programming language to analyze the data. Three regression assumptions, including normality, independence of errors, and homoscedasticity of residuals were met. However, the data did not meet linearity. To fix nonlinearity, we transformed several variables using $\log (\mathrm{X})$. Using the variance inflation factor (VIF), no evidence of multicollinearity was observed. To know how well the results will generalize to other data sets we used k-fold cross-validation. The model to be tested was as follows: VISITS $\sim \log ($ POPUST $)+\log ($ NLIB $)+\log ($ TOTOPEXP $)+B K V O L+\log ($ EBOOK $)+$ $A U D I O P H+\log ($ VIDEOPH $)+\log (L O A N F M)+\log ($ KIDPRO $)+\log ($ YAPRO $)+\log ($ PITUSR $)$ 


\section{FINDINGS}

In 2015, nearly 311 million Americans lived within a public library service area. Public libraries in the U.S. have offered 4.7 million programs in 2015, which were attended by 106 million people. Results indicated that the best subset model for predicting VISITS included NLIB, TOTOEXP, BKVOL, AUDIOPH, KIDPRO, YAPRO, and PITUSR, with an adjusted R-square of 0.88 . Removing other variables from the model significantly increases the predictive power of the model. Therefore, the best model to predict VISITS would be as follows: VISITS $\sim \log ($ NLIB $)+\log ($ TOTOPEXP) + BKVOL + AUDIOPH $+\log ($ KIDPRO $)+\log ($ YAPRO $)+\log ($ PITUSR $)$.

Cross-validation was used to evaluate the generalizability of our regression equation. Cross-validation indicated that the model predicts $79 \%$ of VISITS in practice. Figure 1 shows that TOTOPEXP, PITUSR, AUDIOPH, KIDPRO, and VIDEOPH were the best predictors of VISITS, respectively.

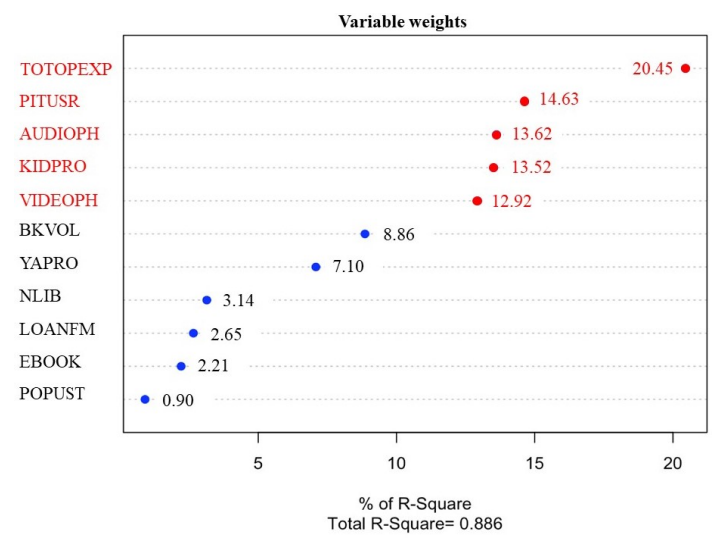

Figure 1. Dot chart of the relative importance (weights) of predictor variables of public library visits in the U.S. Larger weights indicate relatively more important predictors.

\section{DISCUSSION}

TOTOPEXP was the most important factor predicting $20.45 \%$ of VISITS. Salaries and wages for all library staff, as well as the employee benefits for all library staff, may motivate library staff to provide better services and programs, consequently leading to more VISITS. In this regard, Mezick (2007) found a statistically significant relationship between the total academic library expenditures and student retention.

We found that PITUSR predicts $14.63 \%$ of VISITS. Internet technology infrastructure in public libraries appears to be an important factor for attracting people to the public libraries. Internet access in public libraries would contribute to offering other services including licensed databases, homework resources, virtual reference services, ebooks, and audio content (Bertot et al., 2008).

In contrary to some previous studies, such as Sin and Kim (2008), we found that NLIB only predicts $3.14 \%$ of VISITS. It may be argued that alongside the number of public library services (e.g. children's programs), their quality matters too.

The major implication of the study is that to attract more visitors, public libraries should increase their expenditures for both electronic and print materials; public Internet access and youth and adult programs.

Limitation: If there is any evidence of interaction among the variables, the model that includes the interaction term is superior to the model that contains only the main effects. Further studies should take interactions into consideration.

\section{CONCLUSION}

Public libraries with higher expenditures, audio- and video-physical units, programs for a variety of age groups, public Internetenabled computers, and print materials experience more VISITS.

\section{REFERENCES}

Bertot, J. C., McClure, C. R., \& Jaeger, P. T. (2008). Public libraries and the Internet 2007: Issues, implications, and expectations. Library \& Information Science Research, 30(3), 175-184.

Clubb, B. H. (2009). Public Libraries. In Encyclopedia of Library and Information Sciences, Third Edition. (pp.4347-4366). Taylor \& Francis.

Hemmeter, J. A. (2006). Household use of public libraries and large bookstores. Library \& Information Science Research, 28(4), 595-616.

Joo, S., \& Cahill, M. (2017). The relationships between the expenditures and resources of public libraries and children's and young adults' use: An exploratory analysis of Institute of Museum and Library Services public library statistics data. Journal of Librarianship and Information Science, 1-10.

Mezick, E. M. (2007). Return on investment: Libraries and student retention. The Journal of Academic Librarianship, 33(5), 561-566.

Sin, S. C. J., \& Kim, K.S. (2008). Use and non-use of public libraries in the information age: A logistic regression analysis of household characteristics and library services variables. Library \& Information Science Research, 30(3), 207-215.

\section{COPYRIGHT}

The standard copyright permission is included. This may be to be modified should you wish copyright to be retained by someone other than the authors.

$81^{\text {st }}$ Annual Meeting of the Association for Information Science \& Technology | Vancouver, Canada | Nov. 10 - 14, 2018

Author(s) Retain Copyright 